\title{
ANALYSIS OF ECONOMIC AND SOCIAL INDICATORS IN OPTIMIZING THE PERFORMANCE OF URBAN GREEN SPACE MANAGEMENT (A STUDY OF MASHHAD METROPOLIS)
}

\author{
Mohammad Hadi Hossieni SARCHESHMEH \\ Ferdowsi University of Mashhad, Mashhad, Faculty of Letters \& Humanities, \\ Department of Geography, Park Square, 9177948974, Mashhad, Iran, e-mail: Sarcheshmehhadi@ gmail.com \\ Barat Ali KHAKPOOR* \\ Ferdowsi University of Mashhad, Mashhad, Faculty of Letters \& Humanities, \\ Department of Geography, Park Square, 9177948974, Mashhad, Iran, e-mail: Khakpoor@um.ac.ir \\ Mohammad Ajza SHOKUHI \\ Ferdowsi University of Mashhad, Mashhad, Faculty of Letters \& Humanities, \\ Department of Geography, Park Square, 9177948974, Mashhad, Iran, e-mail: Shokuhim@um.ac.ir

\section{Mohammad Rahim RAHNAMA} \\ Ferdowsi University of Mashhad, Mashhad, Faculty of Letters \& Humanities, \\ Department of Geography, Park Square, 9177948974, Mashhad, Iran, e-mail: Rahnamarahim@gmail.com
}

\begin{abstract}
Citation: Sarcheshmeh, M.H.H, Khakpoor, B.A., Shokuhi, M.A., \& Rahnama, M.R. (2020). ANALYSIS OF ECONOMIC AND SOCIAL INDICATORS IN OPTIMIZING THE PERFORMANCE OF URBAN GREEN SPACE MANAGEMENT (A STUDY OF MASHHAD METROPOLIS. GeoJournal of Tourism and Geosites, 32(4), 1370-1375. https://doi.org/10.30892/gtg.32426-582
\end{abstract}

\begin{abstract}
In recent decades, Mashhad as the second largest city of Iran after Tehran has experienced rapidly physical expansion regardless of the citizens' need for green space. The importance of Mashhad's urban green space is understandable from two dimensions, the first one is the existing population of the area and its increasing trend as the second most populous city of Iran and the other is the religious position of Mashhad, which annually receives millions of domestic and foreign travelers. Therefore, the aim of this paper is the investigation of urban green spaces performance in term of economic and social indicators in the Mashhad metropolis area. This research is an applied study by considering to its goal, and a descriptiveanalytical study for respect to its nature. It was also predominantly carried out with a quantitative approach. The statistical population for this research included the total population of Mashhad, and 380 peoples were selected as the sample using Cochran's formula. Also, 20 managers of Mashhad green space were interviewed to obtain more accurate data. SPSS software was used in the form of Cronbach's alpha test and the looseness and elongation index. Data and information reliability were also analyzed by statistical tests. SPSS software was used in the form of Cronbach's alpha test and the looseness and elongation index. Also, data and information reliability were analyzed by statistical tests. Data collection tools included a questionnaire and measurement of items is based on the Likert spectrum and 5-choice options. The research questionnaire includes 15 social questions and 5 economic questions that have been tested and analyzed using SPSS22 software. The results showed that managerial performance in the field of urban green spaces in Mashhad metropolis did not have a significant effect. From the view of citizens and managers, the various dimensions of the social index (communication, education, leisure, access and participation) have been evaluated as desirable.
\end{abstract}

Key words: Social index, Green Space, Mashhad Metropolis, Urban Management

\section{INTRODUCTION}

Positive perceptions of green and open space are only surpassed by dwelling characteristics as important predictors of high 1 evels of neighborhood satisfaction (Russell et al., 2018). A proper assessment of the role and benefits of green spaces (GS) for urban residents is an important concern in the emerging area of urban ecosystem services (ES). Since the last decennium of the 20th century, the concept of ES has gained an important role in the debate on sustainability and quality of life (Burkhard et al., 2010). Also, on the policy level, more attention and action are directed to the dependence of man on nature and its ecosystems. In urban areas, the a spect of non-material benefits or cultural ES is highly relevant (Qu et al., 2017) and GS quality is a major factor for how people receive cultural ES. To reinforce this link in urban areas, an understanding of the quality and management of urban ecosystem services is required to ensure sustainable urban planning (Lüderitz et al., 2015) and general wellbeing. Urban green spaces (UGS) have been the subject of a wide range of studies, yet correlations with assumed benefits have been often based on their presence or abundance, and less based on their qualities (Kabisch and Haase, 2013). So, Green spaces are a complement of urban physical structure. These spaces are a type of urban land-use that has ecological, social and economic traits. On the other hand, today planning and design are adaption green space networks (Ericson, 2004).

Today, urban green spaces are introduced as an appropriate method for the promotion of life quality due to impressive social and ecological influences. So, urban green space is an important issue due to creating a beautiful landscape, also it is an obstacle to air pollution in cities. The function of urban green space is divided generally into three main groups of city structure, ecological function and social performance. Urban green spaces are valuable not only for environmental reasons but also for its role in the development of spiritual and physical relations of inhabitants of the city (Bonnes, 1999). Thus, city green space is a sort of urban land use covered with manmade vegetation, boasting both social and ecological outputs. Besides, these spaces are the basic elements of the city landscape and the symbols of urban life and environmental health (Razzaghian and Rahnama, 2012). The literature on UGS dynamics has revealed the loss, isolation, and fragmentation of UGS in some countries. On the other hand, Van Herzele and Wiedemann (2003) studied the poor accessibility of UGS in Kortrijk (Belgium) and revealed that many inhabitants of the city do not enjoy even one single green space due to urban barriers. Similarly, according to Lee et al. (2013), a high level of spatial disparity prevents some inhabitants from accessing large parks. This trend has appeared particularly in Asian developed countries. Several recent studies, however, point to the importance of assessing urban green space quality (Velarde et al., 2007; Bertram and Rehdanz, 2015).

\footnotetext{
${ }^{*}$ Corresponding author
} 
Rather than a biased preoccupation with green-space acreage and tree counts, planners should also consider the geometry of the green network and the quality of the greenery (Heydari et al., 2016) and the various aspects of GS quality (Bertram and Rehdanz, 2015). Good quality urban green improves the quality of life in cities enhancing their attractiveness to residents, employees, tourists, investors, and firms. On these grounds, urban green space can have a positive contribution to the competitiveness of cities (Figure 1).

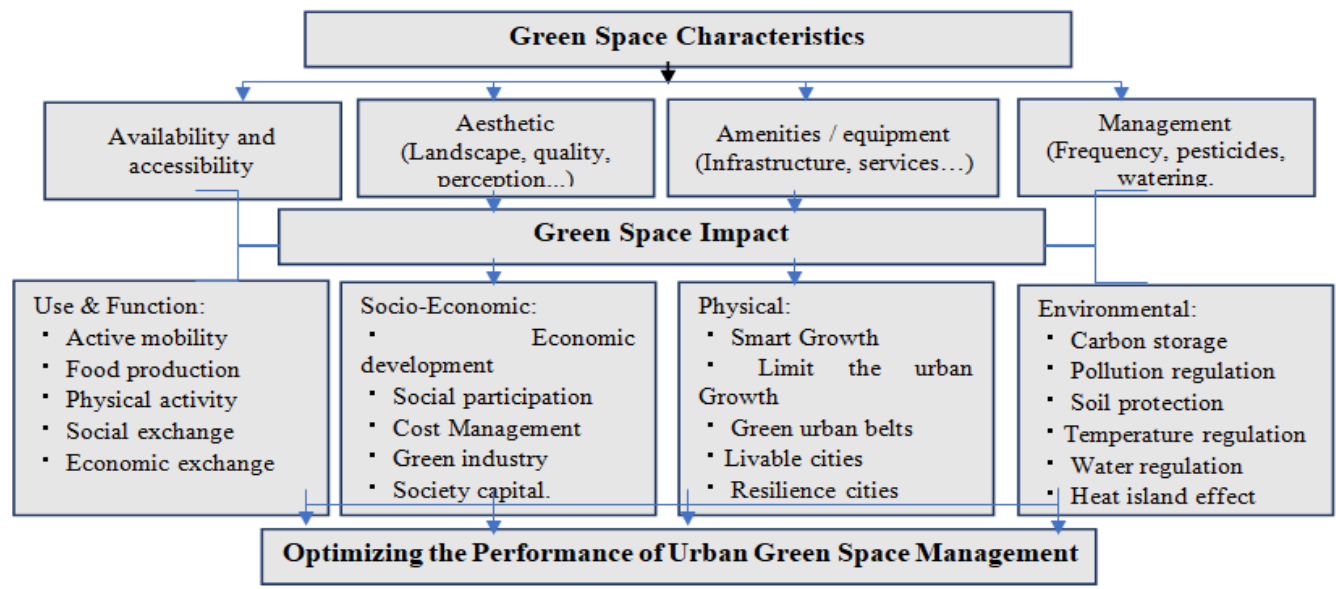

Figure 1. The characteristics and impacts of urban green spaces and its dimensions (Source: Tavakoli and Heydari, 2012)

Alongside these economic effects, however, there are also social and environmental benefits. Parks, gardens, and squares, provide opportunities for relaxation and recreation, as well as for association and social interaction and they help communities to shape their identity and to strengthen their social fabric. In addition, by providing clean air, water, and soil and by helping to stabilize urban temperatures and the urban climate, they support the development of a healthy urban environment in harmony with the natural world. Overall, it can be argued that a good quality of urban green space provides an interacting set of economic, social, environmental and aesthetic benefits and that investing in green spaces can reverse the urban decline and improve the well-being of communities (CABE Space, 2004).

Urban living limits access to nature and can increase exposure to certain environmental hazards, such as air and noise pollution. Many urban areas face increasing pressure from expanding populations, limited resources, social and economic challenges and growing impacts of climate change. These challenges must be addressed in order for cities to provide healthy and sustainable living e nvironments (World Health Organization, 2020). Despite the numerous benefits that urban green spaces provide, there is a considerable lack of studies on the value local residents attach to such spaces (Land Use Consultants, 2004; CABE Space, 2005). This is because urban gree n spaces are 'public goods' and therefore are not traded in conventional markets (Pearce, 1976, 1999). Their benefits are 'external' to the market and this adds to the difficulty confronted in attempting to assess the economic aspects of urban green. This paper presents the investigation of urban green spaces performance in terms of economic and social indicators in the Mashhad metropolis area. So, the main question of this research is consisting of what is the performance of urban green space management in the Mashhad metropolis according to socio-economic dimensions, and what strategies can be provided to improve or solve the challenges?

\section{The theoretical framework of research}

An important role that green spaces play in cities and towns has been acknowledged to various degrees ever since the end of the 19th century (Goede et al., 2000). However, over the last 15 years or so, there has been a resurgence of interest in urban green spaces. According to Swanwick, et al. (2003), this was driven by many factors, including the apparent decline of both quantity and quality of urban green (as a result of low priority in the local authorities' political agendas), the key position green space holds in the concept of 'compact city' which has seen increasing attention in the literature (Burton, 2000) and the growing emphasis on bro wnfield development which exerts pressure on the urban green land to be given to alternative uses. The term green space appeared in the literature of cityplanning from less than half a century ago. Urban green space is referred to a city land with a human-made vegetating covering that yields both ecologically and socially. Ecologic yield means beautification of city parts, reduction of environmental temperat ure, production of oxygen, an increase of soil penetration against rainfall, and conservational gre en spaces constitute living parts of the city's physical structure. The increase of population, growth of cities, the birth of metropolis and conversion of the traditional and natural bodies of cities are always driving the need for green spaces (Heydari and Bakhtar, 2018). According to Pourahmad (2009), the green spaces cause human mental health and security and, in many cases, they are the most important factors in mediating environmen tal pollution burden. Green spaces fulfill aesthetical needs of citizens and they are also important in meeting urban society's health, environmental, psychological and social wishes and expectations. To set forth the issue of green space is necessary for city- dwelling, because it has a direct role in city beautification and citizens comfort level, in addition to its' unique environmental values such as airconditioning and temperature modification (Khosh-Khui, 2002). These spaces are very important, firstly because of their environmental roles, and secondly because they serve as cultural and recreational places for free time (Chehrzad and Azarpishe, 1992).

The economic and ecological benefits of urban green spaces are undeniable. The green industry is one of the fastest growing segments of the nation's agricultural economy and has produced roughly 1,964,339 jobs, according to a USDA-funded research report. The green industry is made up of green roof construction, sustainable landscaping, waste reduction services, arborists, garden centers, lawn care services, and many more (Hall et al., 2011). In the most simplistic terms, the green industry are economies striving towards a more sustainable development. Adopting policies that advocate for the green industry and green spaces in Springfield, MA would improve the economy and environmental health of the city and its inhabitants. These policies would act as solutions to some of the environmental problems that municipalities encounter, due to the natural benefits of green spaces (Fontes et al., 2014). Recent research by many scholars has emphasized the significance of open green spaces as an ideal space for people to meet each other, or as a focus for the community, both formally and informally (Woolley, 2003). They also provide space for socializing, political discourse and cultural expression. The existence of trees (and their shade) as well as grass in public areas can be an attraction for people to spend more time outdoors, which improves social interaction among the members of the community (Coley et al., 1997). There is a great potential for social interaction in open green spaces 
because of the easy access to these spaces, in comparison with the other spaces in a city. Also, there can be greater social unity among the people who interact in leisure activities (organizing public ceremonies, track and field, cycling) which connect them together.

From a social perspective, green space has an impact on a wide range of issues ranging from community involvement and empowerment, to matters of safety, inclusion, equality, civic pride, educations and recreation (Land Use Consultants, 2004). In particular, scholars have pointed out that well managed and maintained green spaces contribute to social inclusion and social justice provide cultural links and opportunities for community events and outdoor association between people, provide an educational resource with regard to environment and nature (Nicol and Blake, 2000) afford recreation, exercise and play for all ages and contributes to the physical, psychological and mental health of the people. Therefore, this paper with emphasize on pervious researches, tries to investigate the status of economic and social indicators in optimizing the performance of urban green space management in Mashhad area.

\section{STUDY AREA}

Mashhad is the second most populous city in Iran and the capital city of the Razavi Khorasan Province. It is located in the northeast of the country, close to the borders of Turkmenistan and Afghanistan. Mashhad city population was 2,749,374 at the 2011 censu s and its built-up area was home to 2,782,976 inhabitants including Mashhad and Torqabeh cities (Heydari and Bakhtar, 2018). The city is most famous and revered for housing the tomb of Imam Reza and every year several millions of pilgrims visit the Imam Reza shrine and pay their tributes to Imam Reza (Wikipedia, 2016; Mashhad Municipality, 2016). It has an area of $148 \mathrm{~km}^{2}$ in 2016 and it has witnessed rapid growth in the last two decades, mostly because of its economic, social and religious attractions. Since 1987, its population has grown 3.6 times while its extent at the same time period has doubled (Rafiee et al., 2009) (Figure 2). According to our findings in this paper, Table 1 shows the development of urban green spaces in the Mashhad area from 2006 to 2018 (Figure 3).

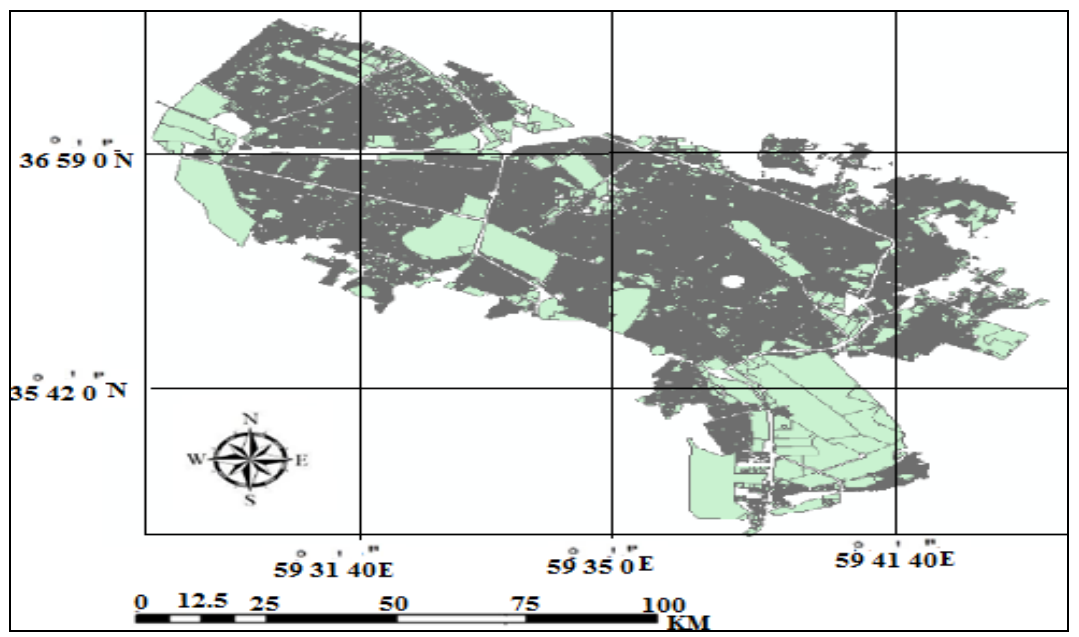

Figure 2. A view of Study Area (Source: Heydari et al., 2019)

Table 1. Urban green spaces in the Mashhad area between 2006 to 2018 (Source: Research findings, 2020)

\begin{tabular}{|c|c|c|c|}
\hline Green spaces & 2006 & 2012 & 2018 \\
\hline green spaces area $\left(\mathrm{m}^{2}\right)$ & 68822 & 82354 & 102354 \\
\hline The ratio of UGS & 11.6 & 13.5 & 16.5 \\
\hline
\end{tabular}

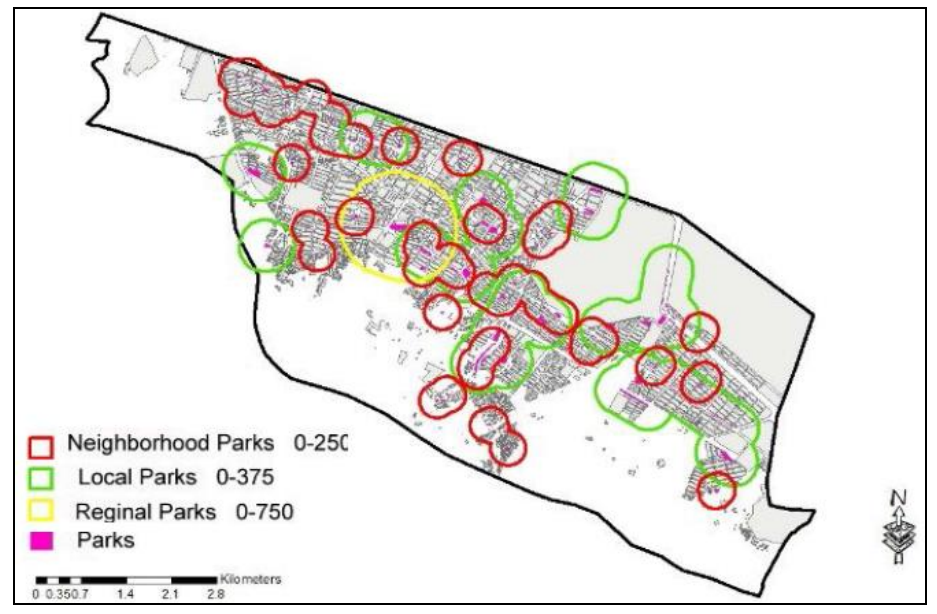

Figure 3. A view of UGS in Mashhad Metropolis (Source: Aghajani and Razzaghian, 2020)

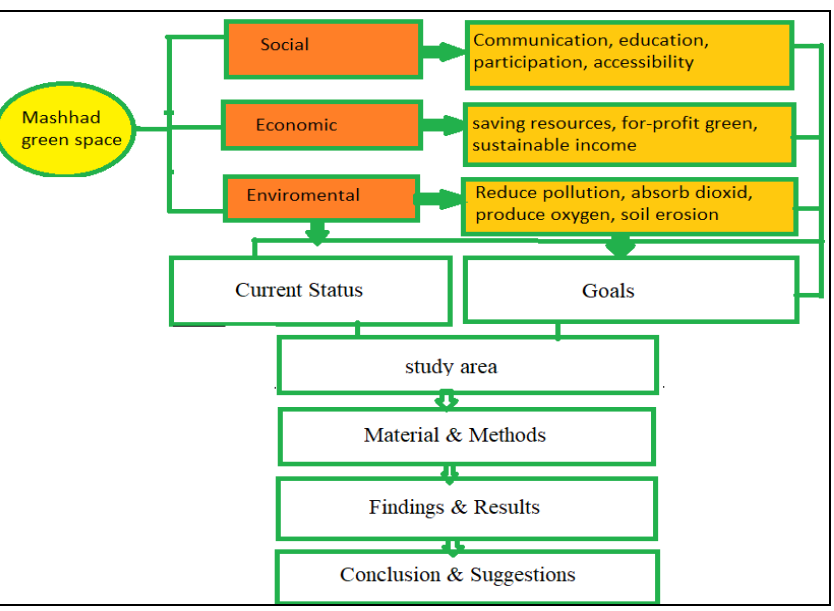

Figure 4. Research conceptual diagram (Source: Authors, 2020)

\section{MATERIAL AND METHODS}

The applied methodology based on its nature is analytical and in terms of results is practical. Further on, we have used descriptiveanalytical studies, documentary, and questionnaire. The required data, based on theoretical and exploratory principles, was gathered through document analysis and field study considering the distance of the land from adjacent land-uses and its compatibility with and dependency on them along with interviews conducted with green space experts and specialists in the Mashhad municipality. 
The statistical population in this study is the total population of Mashhad in 2016 (3,057,679 people) (Iran Statistics Center, 2018). The sample size using the Cochran's formula at the error level of $0.5 \%$ is equal to 380 people and according to the number of parks in Mashhad (575), the performance spectrum questionnaire, whose procedure is confirmed by pre-test, the distribution of the questionnaire has been done among the people and relevant experts, as well as interviews with managers. Finally, using the T-TAC statistical model, an independent sample of the final analysis is performed on the data (Figure 4).

\section{RESULTS \& FINDINGS}

According to the statistics of Mashhad metropolis in 2018, it has 13 regions with over 4 million population, the highest population is related to region 2 and the lowest population is related to the Samen region. According to these statistics, the standard and acceptable per capita urban green space in Iranian cities are between 7 and 12 square meters per person, which in comparison with the united nation' standard (20-25 $\left.\mathrm{m}^{2}\right)$ shows fewer rates. According to Table 2, by considering the official statistics of 2017, the area of urban green space, including park, square, Lachki boulevard and green belt is equal to 439,564,594 square meters, which means that the per capita green space of Mashhad is about 26,14 $\mathrm{m}^{2}$ for each person. The metropolis of Mashhad has 575 parks with an area of 809,217,12 square meters, which includes about $28 \%$ of the total green space in terms of number (Mashhad Municipality, 2018). Also, the highest number of parks is located in District 10 and the lowest park rate is related to District 4. In terms of area, the largest area is related to District 7 with 2,736,894 square meters and the lowest area is related to the Samen area with 44,736 square meters. The standard of green space per capita which is declared by the United Nations is $20-25$ square meters and is related to the green space of the city park and for leisure, and does not include the green spaces of the street, including the Icelanders, boulevards, alleys, etc. The green space of Mashhad per capita by attention global standards will be unacceptable. On the other hand, the distribution of urban green spaces in Mashhad is very unbalanced, which indicates the lack of proper urban studies and planning by consultants, and this is important for unnecessary population relocation and the result will impose more transportation costs and consequently air pollution.

Table 2. Number and area of parks in Mashhad city by region (Source: Research Findings, 2020)

\begin{tabular}{|c|c|c|c|c|}
\hline Regions & Total UGS & UG per capita & Number of parks & Area \\
\hline 1 & 687761 & $4 / 12$ & 39 & 359,377 \\
\hline 2 & 2085614 & $4 / 06$ & 74 & 775,038 \\
\hline 3 & 1867989 & $4 / 47$ & 48 & 840,078 \\
\hline 4 & 1406648 & $5 / 37$ & 12 & 523,966 \\
\hline 5 & 811166 & $4 / 62$ & 34 & 528,886 \\
\hline 6 & 1176353 & $5 / 06$ & 44 & 655,736 \\
\hline 7 & 6922351 & $27 / 34$ & 35 & $2,736,894$ \\
\hline 8 & 1749421 & $18 / 90$ & 23 & $1,087,670$ \\
\hline 9 & 21936292 & $67 / 08$ & 87 & $2,333,145$ \\
\hline 10 & 2227512 & $7 / 50$ & 99 & 966,067 \\
\hline 11 & 1880514 & $9 / 40$ & 41 & $1,087,874$ \\
\hline 12 & 773749 & $7 / 35$ & 26 & 278,382 \\
\hline Samen & 71094 & $5 / 13$ & 13 & 44,736 \\
\hline Total & 43599564 & $14 / 26$ & 575 & $12,217,809$ \\
\hline
\end{tabular}

According to the efforts made, the green space of Mashhad per capita in 2019 has increased to 16.62 square meters, which has increased by 2.36 percent. What is important is that the green space per capita of the United Nations is only for recreation, and if we only calculate and analyze the parks that are places of recreation (807/217/129 square meters), the green space per capita will be about 4 square meters, which will be increasing the green space standards in the study area. Mashhad's 4,359-hectare green space budget is 400 million Tomans annually. That is, the cost of each square meter of green space is about 10 thousand Tomans. Annually, one-eighth of the budget of 400 billion Tomans of green space in Mashhad (equivalent to 50 billion Tomans) is spent to welcome Nowruz, which is a very short-term work of 2 months, and according to experts, if we pay 100,000 Tomans per square meter of the urban park, the amount of 50 hectares of one-hectare city park can be implemented. Non-priority and short-term work, which is only in front of people's eyes, not only does not help the sustainable development of green space but also it will be wasting public funds. Although many efforts have been made in recent years to mechanize urban green space, including drip or rain, $133.83 \%$ are still flooded and non-mechanized, and $86.17 \%$ are mechanized through pressure networks.

\section{Analysis the findings of the questionnaires}

After studying the theoretical foundations and background of the research, hypotheses were proposed that were designed to test the hypotheses of the questionnaire containing questions related to the characteristics of the respondents and also questions to test the hypotheses. In this section, SPSS22 software and its tests including Descriptive and Frequencies were used to analyze descriptive and inferential findings to analyze descriptive statistics including calculation of frequencies, percentage of frequencies, cumulative frequency and averages.

Table 3. Economic index in the view of experts and managers (Source: Authors, 2020)

\begin{tabular}{|c|c|c|c|c|}
\hline index & dimension & variables & avg & Total avg \\
\hline \multirow{9}{*}{ 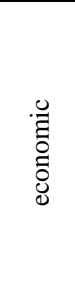 } & \multirow{4}{*}{ Resource storage } & Right species with the climate & $3 / 3$ & \multirow{4}{*}{$3 / 2$} \\
\hline & & Right irrigation method & $3 / 4$ & \\
\hline & & Soil type suitable for creating green space & $3 / 3$ & \\
\hline & & Use of urban effluent & $2 / 7$ & \\
\hline & Profitable green space & Providing goods needed by tourists & $2 / 7$ & $2 / 7$ \\
\hline & \multirow{3}{*}{$\begin{array}{l}\text { Outsourcing and } \\
\text { revenue absorption }\end{array}$} & Suitable facilities to attract foreign tourists & $2 / 9$ & \multirow{3}{*}{$2 / 5$} \\
\hline & & Attract private investors to expand green space & $2 / 7$ & \\
\hline & & Taxes and levies & $2 / 1$ & \\
\hline & & Avg of whole economic index & & $2 / 6$ \\
\hline
\end{tabular}

\section{The status of the economic index in the view of experts and managers}

The economic index examined in the present study has dimensioned such as resource storage, for-profit green space, outsourcing, and sustainable revenue attraction for the municipality. Table 3 shows the average of the total in each dimension of the economic index and also the 
average of each variable in the economic dimension of the whole city of Mashhad. According to this table, the total average in the economic index (2.6) is the highest average in the dimensions of the economic index related to resource storage (3.2) and the lowest average is related to outsourcing and attracting sustainable income for the municipality is (2.5). Also, the lowest mean between the variables is related to the question about the tax, and tolls (2.1), and the highest average in the variables is related to the question of choosing the appropriate irrigation method (3.4).

\section{Dimensions of social indicators of Mashhad city parks}

The social index of the present study includes five dimensions of communication, education, recreation, access, and participation.

Table 4 shows the average of the total in each dimension of the social index and also the average of each variable in the social dimension of the whole city of Mashhad. According to this table, the total average in the social index (2.02), which the highest average is related to the dimension of the promenade (2.54) and the lowest average is related to the dimension of participation (1.60). Also, the lowest mean in the variables was related to the question of the level of participation in local organizations regarding the preservation of green space (1.60), and the highest average in the variables was related to the place for recreation with a score about (3.36). Table 4 shows the average of social indicators from the view of citizens and managers. It should be noted that the score of the items is between 1 and 5 . This means that if we consider the level from 1 to below 3 as low, and 3\% as average, and from 3 and above as excellent. According to the table, in terms of managers, social indicators (3.8) are higher than the average level. However, from the citizens' point of view, this index is similarly low (2.02). The biggest difference from the perspective of these two groups is related to the social index in terms of communication and education.

Table 4. Dimensions of social indicators of Mashhad city parks (Source: Authors, 2020)

\begin{tabular}{|c|c|c|c|c|}
\hline index & dimension & variables & avg & Total avg \\
\hline \multirow{16}{*}{$\begin{array}{l}\bar{\pi} \\
\text {. } \\
\tilde{S}\end{array}$} & \multirow{2}{*}{ communication } & As a good place for daily meetings & 2.06 & \multirow{2}{*}{1.83} \\
\hline & & As a good place to socialize with people & 1.61 & \\
\hline & \multirow{2}{*}{ education } & Carrying out cultural activities & 1.96 & \multirow{2}{*}{1.81} \\
\hline & & Carrying out educational programs for children & 1.66 & \\
\hline & \multirow{5}{*}{ recreation } & A suitable space for group circulation (picnic) & 2.52 & \multirow{5}{*}{2.54} \\
\hline & & Suitable equipment for entertainment & 1.86 & \\
\hline & & A good place to exercise & 2.35 & \\
\hline & & A good place to walking & 3.36 & \\
\hline & & A good place to receiving medical services & 2.58 & \\
\hline & \multirow{5}{*}{ accessibility } & A good walking path to access the park & 2.40 & \multirow{5}{*}{2.32} \\
\hline & & The proximity of the park to educational centers & 2.30 & \\
\hline & & Proximity of the park to residential centers & 2 & \\
\hline & & Traffic situation of urban green space route & 2.11 & \\
\hline & & Access to public transportation & 2.78 & \\
\hline & participation & Participation of local organizations in the maintenance of green space & 1.60 & 1.60 \\
\hline & \multicolumn{3}{|c|}{ Avg of whole social index } & 2.02 \\
\hline
\end{tabular}

\section{CONCLUSION AND HYPOTHESIS TEST}

First hypothesis: It seems that the use of irrigation methods and suitable plant species with climate, suitable soil, and the use of effluents in irrigation of green space will also help to improve economic performance and optimize urban green space management. Based on the singlesample T-test, the significance level is 0.004 and less than 0.05 . Therefore, the H0 hypothesis, the opposite hypothesis, that is, modification of irrigation methods, suitable plant species, use of suitable effluents and soil, helps to improve and economic performance, is confirmed.

Second hypothesis: It seems that local programs and strengthening people's participation will help improve social performance and optimize Mashhad's urban green space management. According to the results of the p-value test in the social index in the citizens' section (zero), which is less than 0.05 , the $\mathrm{H} 0$ hypothesis is rejected and the opposite hypothesis, which seems to be local planning and strengthening people's participation to improve social performance and optimize management. Mashhad's urban green space helps, is confirmed.

\section{CONCLUSION AND SUGGESTIONS}

In recent decades, Mashhad as the second largest city of Iran after Tehran has experienced rapidly physical expansion regardless of the citizens' need for green space. The importance of Mashhad's urban green space is understandable from two dimensions, the first one is the existing population of the area and its increasing trend as the second most populous city of Iran and the other is the religious position of Mashhad, which annually receives millions of domestic and foreign travelers. Therefore, the aim of this paper is the investigation of urban green spaces performance in term of economic and social indicators in the Mashhad metropolis area. This research is an applied study by considering its goal, and a descriptive-analytical study for respect to its nature. Good quality urban green improves the quality of life in cities enhancing their attractiveness to residents, employees, tourists, investors, and firms. On these grounds, urban green space can have a positive contribution to the competitiveness of cities. So, the main question of this research is consisting of what is the performance of urban green space management in the Mashhad metropolis according to socio-economic dimensions, and what strategies can be provided to improve or solve the challenges? The highest number of parks is located in District 10 and the lowest park rate is related to District 4 . In terms of area, the largest area is related to District 7 with 2,736,894 square meters and the lowest area is related to the Samen area with 44,736 square meters. The green space per capita declared by the United Nations is $20-25$ square meters and is related to the green space of the city park and for leisure, and does not include the green spaces of the street, including the Icelanders, boulevards, alleys, etc. The green space of Mashhad per capita by attention global standards will be unacceptable. On the other hand, the distribution of urban green spaces in Mashhad is very unbalanced, which indicates the lack of proper urban studies and planning by consultants, and this is important for unnecessary population relocation and the result will impose more transportation costs and consequently air pollution. According to Table 4, the total average in the social index (2.02), which the highest average is related to the dimension of the promenade (2.54) and the lowest average is related to the dimension of participation (1.60). Also, the lowest mean in the variables was related to the question of the level of participation in local organizations regarding the preservation of green space (1.60), and the highest average in the variables was related to the place for recreation with a score about (3.36). Therefore, we can offer some suggestions as below:

* Providing sustainable water resources and increasing irrigation efficiency due to the special climatic and low water conditions of Mashhad city. 
* Use of effluents and gray waters.

* Use of technical and correct methods to irrigation UGS.

* Mechanization of the entire green space system through a pressure network and completion of Mashhad city loop and moving towards drip and rain systems instead of traditional and flooding systems.

* Use of suitable plant species with the climate of Mashhad metropolis.

* Apply the right methods of planting and maintaining urban green space in the study area.

\section{REFERENCES}

Bertram, C., \& Rehdanz, K. (2015). The role of urban green space for human well-being. Ecological Economics, 120, 139-152. https://doi.org/10.1016/j.ecolecon.2015.10.013

Bonnes, M., (1999). The ambivalence of attitudes toward urban green areas: Between PR environmental worldviews and daily residential experience. Environment and Behavior, 43(2), 207-232. https://doi.org/10.1177/0013916509354699

Burkhard, B., Kroll, F., Nedkov, S., \& Müller, F. (2010). Mapping ecosystem service supply, demand and budgets. Ecological indicators, 21, 17-29. https://doi.org/10.1016/j.ecolind.2011.06.019

Burton, E. (2000). The compact city: just or just compact? A preliminary analysis. Urban studies, 37(11), 1969-2006. https://doi.org/ $10.1080 / 00420980050162184$

Chehrzad, S., \& Azarpishe, X. (1992). The Prepration of Designing Eco-park Principles, case study: Pardisan Eco-park of Tehran, Environmental Science and Technology magazine, 10(4), 200-233. https://doi.org/10.1177/001391659596546

Coley, R.L., Sullivan, W.C., \& Kuo, F.E. (1997). Where does community grow? The social context created by nature in urban public housing. Environment and behavior, 29(4), 468-494. https://doi.org/10.1177/001391659702900402

Ericsson, U. (2004). Haunting Experiences of Images. Ethnologia Europaea, 34(2). https://doi.org/10.16995/ee.963

Fontes, I., Gomes, E., \& Rocha, J. (2014). Compliance of land cover changes with municipal land use planning: Evidence from the Lisbon metropolitan region (1990-2007). Land Use Policy, 51, 120-134. https://doi.org/10.1016/j.landusepol.2015.10.023

Goede, J., Bjorkman, J., Hollander, A., \& Thorne, J.H. (2000). The structure, function and value of urban forests in California communities. Urban Forestry \& Urban Greening, 28, 43-53. https://doi.org/10.1016/j.ufug.2017.09.013

Hall, R.L., Riley, A., \& Moore, D.R. (2011). Communication, listening, cognitive and speech perception skills in children with auditory processing disorder (APD) or specific language impairment (SLI). Journal of Speech, Language, and Hearing Research, 15(5), 145-149. https://doi.org/10.1044/1092-4388(2010/09-0167

Heydari, A., \& Bakhtar, S. (2018). Analyzing the regional development of Kurdish border cities of Iran using sustainable urban development indices (study area: kurdistan province). GeoJournal of Tourism and Geosites, 23 (3), 797-807. https://doi.org/ 10.30892/gtg.23315-329

Heydari, A., Rahnama, M., Shokouhi, M., \& Kharazmi, O. (2016). Analysis the Spatial Changes of Urban Environment in the Mashhad Metropolis Using the Natural Step Future Study Approach. Geography and Sustainability of Environment, 6(1), 1-19. https://doi.org/10.1080/145784632541

Kabisch, N., Strohbach, M., Haase, D., \& Kronenberg, J. (2013). Urban green space availability in European cities. Ecological indicators, 70, 586-596. https://doi.org/10.1016/j.ecolind.2016.02.029.

Khosh-Khui, M. (2002). Seasonal changes in some physiological and biochemical responses of six groundcover plants. International Journal of Horticultural Science and Technology, 4(1), 105-116. https://doi.org/10.22059/IJHST.2018.216412.151

Lee, D.K., Park, C.Y., \& Jeong, S.G. (2013). The influence of small green space type and structure at the street level on urban heat island mitigation. Urban forestry \& urban greening, 21, 203-212. https://doi.org/10.1007/s10980-019-00932-6

Lrich, H., \& Addoms, I. (1991). Urban green spaces. Wit press. London. WITpress@ @it.uk.com. https://doi.org/10.2495/SDP160311

Lüderitz, V., Langheinrich, U., Arevalo, J.R., Jüpner, R., \& Fernandez, A. (2015). Ecological assessment of streams on La Gomera and Tenerife (Spain)-an approach for an evaluation and restoration tool based on the EU-Water Framework Directive. (this issue). Waldökologie, Landschaftsforschung und Naturschutz, 10, 67-75. 10 https://doi.org/0041-afsv-01087

Wacker, E.M.L., \& Dimitrakopoulos, P.G. (2007). Biodiversity and ecosystem functioning: reconciling the results of experimental and observational studies. Functional Ecology, 21(5), 998-1002. https://doi.org/10.7554/eLife.23255

Nicol, C., \& Blake, R. (2000). Classification and use of open space in the context of increasing urban capacity. Planning practice and research, 15(3), 193-210. https://doi.org/10.1080/713691902

Pearce, L. (1976). Personal encounters with trees: The lived significance of the private urban forest. Urban Forestry \& Urban Greening, 14(1), 1-7. https://doi.org/10.1016/j.ufug.2014.11.003

Pourahmad, A. (2009). Management of Urban Green Space in Zone 9 of Tehran, Iran.

Rafiee, J., Arvani, F., Harifi, A., \& Sadeghi, M.H. (2009). Intelligent condition monitoring of a gearbox using artificial neural network. Mechanical systems and signal processing, 21(4), 1746-1754. https://doi.org/10.1016/j.ymssp.2006.08.005

Razzaghian, F., \& Rahnama, M.R. (2012). Ecological analysis of urban parks (case study: Mashhad Metropolitan). International Journal of Applied,2(7), 136-142. https://doi.org/10.1007/s11524-019-00373-1

Russell, M.L., van Teeffelen, A.J., \& Verburg, P.H. (2018). Quantifying urban ecosystem services based on high-resolution data of urban green space: an assessment for Rotterdam, the Netherlands. Journal of Applied Ecology, 52(4), 1020-1032. https://doi.org/10.1111/1365-2664.12469

Swanwick, C., Dunnett, N., \& Woolley, H. (2003). Nature, role and value of green space in towns and cities: An overview. Built Environment. 3(3), 94-106. https://doi.org/10.2148/benv.29.2.94.54467

Tavakoli, M., \& Heydari, A. (2012). Urbanization in Kurdish cities after The Islamic revolution of Iran, case study Saqqez city. Sustainable Cities and Society, 2(1), 45-49. https://doi.org/10.1016/j.scs.2011.10.003

Van Herzele, A., \& Wiedemann, T. (2003). A monitoring tool for the provision of accessible and attractive urban green spaces. Landscape and urban planning, 63(2), 109-126. https://doi.org/10.1016/S0169-2046(02)00192-5

Velarde, M.D., Fry, G., \& Tveit, M. (2007). Health effects of viewing landscapes-Landscape types in environmental psychology. Urban Forestry \& Urban Greening, 6(4), 199-212. https://doi.org/10.1016/j.ufug.2007.07.001.

Woolley, H. (2003). Urban open spaces, 12 (3), 113-149. https://doi.org/10.4324/9780203402146.

Qu, Z., Xu, R., Pan, K., Xu, B., Min, Y., \& Ge, Y. (2017). Assessing the ecosystem services provided by urban green spaces along urban center-edge gradients. Scientific reports, 7(1), 1-9. https://doi.org/10.1038/s41598-017-11559-5.

**** Iran Statistics Center. (2018). Mashhad Urban Area. City Press. 2 (1), 11-18.

*** Land Use Consultants, (2004) National Audit, landuse.h@gmail.com.

*** Land Use Consultants. (2004). Urban green space. Iran ministry of urbanism. 12 (3), 12-15.

*** Mashhad Municipality. (2016). Urban Green Spaces: annual report. Shahr Ara Press. 12 (4), 124-129.

*** Space, C.A.B.E. (2004). Is the grass greener...? Learning from international innovations in urban green space management. London, UK: Cabe Space. (http://www. cabespace. org. uk/data/pdfs/greenspacestrategies. pdf), 5, 04-12.

*** Wikipedia. (2016). Mashhad urban green spaces. https://en.wikipedia.org/wiki/Mashhad. 